\title{
ATIVIDADE LEISHMANICIDA IN VITRO DE Prosopis juliflora (SWARTZ)
}

SILVA. C. C ${ }^{1}$; SILVA, A. C. M. S ${ }^{1}$; SILVA-LACERDA. G. R'; SILVA. K. M. P² C. M. B. OLIVEIRA-JUNIOR ${ }^{3}$; G. M. CAVALCANTE ${ }^{2,3}$

${ }^{1}$ Acadêmicas do curso de Biomedicina da FACULDADE UNINASSAU-CARUARU. ${ }^{2}$ Docentes do curso de Biomedicina da FACULDADE UNINASSAU-CARUARU.

${ }^{3}$ Universidade de Pernambuco (UPE), Campus Santo Amaro, Centro de Ciências Biológicas.

E-mail para contato: camilacassia1997@hotmail.com

RESUMO - As leishmanioses são infecções causadas por uma variedade de espécies do gênero Leishmania, e é transmitida ao homem por mosquitos flebotomíneos. A quimioterapia é limitada e os fármacos utilizados provocam uma série de efeitos colaterais, além de apresentar altos índices de toxicidade. Na busca de novos agentes foi avaliada in vitro o extrato foliar e frações de Prosopis juliflora frente a formas promastigotas de Leishmania amazonesis. O efeito inibidor do crescimento de formas promastigotas de L. amazonensis foi determinado para o extrato bruto da folha e frações orgânicas, em comparação com a pentamidina, utilizada como droga padrão e os efeitos citotóxicos foram avaliados em células de macrófagos linhagem $J 774$ por ensaio MTT-citotoxicidade. O extrato etanólico (EEtOH) e as frações metanólica (FrMeOH) e acetato de etila (FrAcEOt) exibiram resultados significativos contra a formas promastigotas de $\underline{L}$. amazonesis $\left(C I_{50}=5,1 \pm 0,4 \quad \mu \mathrm{g} / \mathrm{mL} ; \quad C I_{50}=4,9 \pm 0,5 \quad \mu \mathrm{g} / \mathrm{mL} ; \quad C I_{50}=5,0 \pm 1,0 \quad \mu \mathrm{g} / \mathrm{mL}\right.$, respectivamente). Os extratos e frações não afetaram a viabilidade celular de macrófagos J774. Estudo químico para a extração e o isolamento de compostos ativos é recomendado, para realização de ensaios in vitro de substâncias isoladas de $\underline{\text { P.juliflora frente a L. amazonensis. }}$.

PALAVRAS-CHAVES: Prosopis juliflora. Atividade leishmanicida. Atividade citotóxica.

ABSTRACT: Leishmaniosis is an infection caused by species of Leishmania, is
transmitted to humans by phebotomine sandflies. Pentavalent antimonial
compounds are used in the chemotherapy of this disease; however, these drugs
cause several collateral effects, besides presenting high levels of toxicity. The
search for new antileishmanial agents, was investigated in vitro the leaf extract and
organic fractions of Prosopis juliflora against the promastigotes forms of
Leishmania amazonensis. The growth inhibitory effect of promastigote forms of L.
amazonesis was determined for the leaf crude extract and organic fractions of the
in comparison to pentamidine used as standard drug; and the cytotoxic effects were
assessed on macrophage strain J774 by MTT-cytotoxicity assay. Etanolic extracts
(EEtOH), Fraction acetate (FrAcEOt) and methanolic (FrMeOH) exhibited 
significant result against for promastigotes forms of $\underline{L}$. amazonesis $\left(I C_{50}=5.1 \pm 0.4\right.$ $\mu \mathrm{g} / \mathrm{mL} ; I C_{50}=4.9 \pm 0.5 \mu \mathrm{g} / \mathrm{mL} ; I C_{50}=5.0 \pm 1.04 .9 \pm 0.5 \mu \mathrm{g} / \mathrm{mL}$, respectively). Extracts and fractions did not affect cell viability of macrophages J774. A chemical study for the extraction and isolation of active compounds is recommended for the in vitro assay of substances isolated from $\underline{P}$. juliflora against $\underline{L}$. amazonensis.

Keywords: Prosopis juliflora. Leishmanicidal activity. Cytotoxic activity.

\section{INTRODUÇÃO}

As leishmanioses são doenças classificadas pela Organização Mundial de Saúde (OMS) como negligenciadas, endêmicas em mais de 88 países, tendo em média 12 milhões pessoas vivendo em áreas de risco (ALVAR et al., 2015). Trata-se de uma infecção causada por parasitas do gênero Leishmania que são transmitidos por mosquitos pertencentes aos gêneros Phlebotomus (Velho Mundo) e Lutzomya (Novo Mundo), e que é considerada um grande problema de saúde pública, em virtude dos altos índices de morbidade e mortalidade (GRECCO et al., 2012).

$\mathrm{O}$ tratamento desta doença é baseado no uso de antimoniais pentavalentes $(\mathrm{Sb}+5)$ como o Glucantime, fármaco de primeira escolha; além de Anfotericina B e Pentamidina. Apesar de várias opções terapêuticas, o tratamento ainda é considerado limitado em virtude do seu alto custo e longo período; além de alta toxicidade do medicamento (SANTOS et al., 2015). Em virtude disso, a OMS tem estimulado as pesquisas com novos agentes leishmanicidas.

Neste contexto, várias substâncias químicas e extratos de plantas são estudados corriqueiramente com a finalidade de encontrar novos agentes leishmanicidas com menor efeito tóxico, ótima biodisponibilidade e baixa capacidade de desenvolvimento de resistência do parasita (SANTOS et al., 2013).

A espécie vegetal Prosopis juliflora pertencente à família Mimosaceae, é uma espécie exótica, originária do norte da América do Sul e Central, conhecida popularmente como algaroba, com ampla distribuição na Região Nordeste do Brasil, principalmente nos estados da Paraíba, Rio Grande do Norte, Pernambuco, Bahia e Piauí (NASCIMENTO, 2014). Dentre as suas muitas utilizações, é possível destacar suas atividades antimicrobiana (SHACHI-SINGH; VERMA, 2011), antineoplásica (SATHIYA; MUTHUCHELIAN, 2011), antioxidante (NAPAR et al., 2012) e antiplasmodial (RAVIKUMAR et al., 2012).

Com base no amplo espectro de atividades biológicas registradas para a espécie em estudo e a valorização de pesquisas com produtos naturais; além da ineficiência terapêutica, casos de múltipla resistência ao medicamento e ausência de vacinas disponíveis para leishmanioses; o objetivo deste trabalho foi avaliar a atividade leishmanicida do extrato etanólico e frações orgânicas de $P$. juliflora frente a formas promastigotas de L. amazonensis.

\section{MATERIAIS E MÉTODOS}

A espécie vegetal foi obtida junto a Estação Experimental do Instituto Agropecuário de Pernambuco (IPA), situada na cidade de Vitória de Santo Antão, 
Pernambuco, em março de 2017. Diferentes partes vegetais (folha, flor, fruto e talo) foram acondicionadas em sacos plásticos individuais e levadas para confirmação e identificação da espécie por profissionais de Botânica. Uma exsicata foi depositada no Herbário do Instituto Agropecuário de Pernambuco sob o n IPA7611.

Para a obtenção dos extratos, as folhas foram secas à temperatura ambiente e moídas com auxílio de um moinho. Sete quilos do pó foram misturados com etanol a uma concentração de $70 \%$ (v/v) para obtenção do extrato etanólico das folhas (EEtOH). A evaporação do etanol foi realizada utilizando um evaporador rotativo sob vácuo a 30 ${ }^{\circ} \mathrm{C}$. Após evaporação do solvente, uma alíquota de $50 \mathrm{~g}$ de $\mathrm{EEtOH}$ foi suspensa na mistura metanol: água $(1: 1)$ e o resíduo insolúvel $(13,5 \mathrm{~g})$ foi removido por filtração. A solução hidroalcoólica foi particionada sucessivamente com hexano e acetato de etila para produzir 3,1 g da fração orgânica hexânica (FrHex), 11,1 g da fração orgânica acetato de etila (FrAcEOt) e 2,6 g da fração residual metanol: água (FrMeOH). Antes da utilização nos ensaios de atividade leishmanicidas e citotoxicidade em células de linhagens J774, o extrato etanólico e as frações orgânicas foram dissolvidos em dimetilsulfóxido a $0,01 \%$ (DMSO 0,01\%).

$\mathrm{O}$ efeito do extrato e das frações de $P$. juliflora frente a formas promastigotas de L. amazonensis foi realizado pelo método de redução de MTT (Brometo de 3-[4,5dimetil-tiazol-2-il]-2,5-difeniltetrazólio). Formas promastigotas foram cultivadas em placas de 96 poços contendo meio RPMI suplementado com 10\% Soro Fetal Bovino (SBF), $2 \mathrm{mM}$ de L-glutamina e $2 \%$ de urina humana, na concentração de $1 \times 10^{5}$ células/poço. Diferentes concentrações do extrato e das frações de P. juliflora $(0,1,1,10$ e $100 \mu \mathrm{g} / \mathrm{mL}$ ) e do fármaco padrão (Pentamidina) foram adicionados aos poços até a obtenção final de $200 \mu \mathrm{L}$. Para controle de crescimento basal foram usados meio de cultura livre de compostos e meio de cultura contendo o solvente utilizado na solubilização do extrato e das frações (DMSO 0,01\%). As placas foram incubadas em estufa B.O.D a $27^{\circ} \mathrm{C}$ por 48 horas. Após o período de incubação, o sobrenadante foi descartado e em seguida foi adicionado $20 \mu \mathrm{L}$ de solução de MTT ( $2 \mathrm{mg} / \mathrm{mL})$. As placas foram incubadas por 2 horas em estufa a $37{ }^{\circ} \mathrm{C}$ e a $5 \%$ de $\mathrm{CO}_{2}$. Transcorrido o período de incubação, após o descarte do sobrenadante, foi adicionado $120 \mu \mathrm{L}$ de Isopropanol. As placas foram mantidas em repouso por 1 hora a temperatura ambiente. A leitura foi realizada em espectrofotômetro a $550 \mathrm{~nm}$. Os ensaios foram realizados em triplicatas e os dados obtidos foram expressos como a média \pm desvio $(\mathrm{X} \pm \mathrm{DP})$.

$\mathrm{O}$ estudo de viabilidade celular do extrato bruto e das frações foi realizado frente a macrófagos da linhagem J774 pelo método de redução de MTT, conforme descreve a metodologia de Mosmann (1983). Os macrófagos foram semeados em placas de 96 poços na concentração de $1 \times 10^{5}$ células/poço e expostos a diferentes concentrações dos extratos e das frações $(0,1,1,10$ e $100 \mu \mathrm{g})$, diluídas em meio RPMI suplementado com $10 \%$ de soro fetal bovino (FBS) e $2 \mathrm{mM}$ de $L$-glutamina, aminoácidos não essenciais e piruvato, por um período de 48 horas em estufa a $37{ }^{\circ} \mathrm{C}$ com atmosfera úmida contendo $5 \%$ de $\mathrm{CO}_{2}$. Como controle de crescimento basal, as células foram cultivas em meio de cultura livre de compostos, e em meio de cultura contendo DMSO 0,01\%, e para o controle de células mortas foi adicionado Triton 1\% ao meio RPMI suplementado. Transcorrido o período de incubação, o sobrenadante foi descartado e logo após foi adicionado $100 \mu \mathrm{L}$ da solução de MTT $(5 \mathrm{mg} / \mathrm{mL})$. As placas foram novamente incubadas por 1 hora em estufa a $37{ }^{\circ} \mathrm{C}$ e a $5 \%$ de $\mathrm{CO}_{2}$. Em seguida, após a retirada do sobrenadante foi adicionado $100 \mu \mathrm{L}$ de DMSO 0,1\% e realizada a leitura em espectrofotômetro a $550 \mathrm{~nm}$. Os ensaios foram realizados em triplicatas e os dados obtidos foram expressos como a média \pm desvio padrão $(\mathrm{X} \pm \mathrm{DP})$. 
A análise estatística foi realizada com o programa BioEstat 5.0 As diferenças entre os grupos controles e experimentais foram realizadas através da análise de variância (ANOVA) seguido do teste de Dunnett. Os valores foram considerados significativos quando $\mathrm{p}<0,05$ foi comparado ao grupo controle.

\section{RESULTADOS E DISCUSSÃO}

Os efeitos do EEtOH e das frações FrHex, FrAcEOt e FrMeOH de P. juliflora frente a formas promastigotas de L. amazonensis e a macrófagos da linhagem J774, usando o método de redução de MTT, são apresentados na tabela 1.

Tabela 1 - Efeitos da Pentamidina, EEtOH, FrHex, FrAcEOt, FrMeOH de Prosopis juliflora frente a formas promastigotas de L. amazonensis e macrófagos da linhagem J774.

\begin{tabular}{c|cc|cc}
\hline \multirow{2}{*}{ Tratamento } & Leishmania & amazonensis & Macrófagos & J774 \\
\cline { 2 - 5 } & $\mathbf{C I}_{\mathbf{5 0}}{ }^{\mathbf{a}}$ & $\mathbf{E M ~ ( \% ) ^ { \mathbf { b } }}$ & $\mathbf{C I}_{\mathbf{5 0}} \mathbf{c}^{\mathbf{d}}$ & $\mathbf{E M ~ ( \% )}^{\mathbf{d}}$ \\
\hline Pentamidina & $2,5 \pm 1,0 \mu \mathrm{M}$ & $92,4 \pm 0,5^{* * *}$ & $1,5 \pm 0,5$ & $91,0 \pm 1,0^{* * *}$ \\
EEtOH & $5,1 \pm 0,5 \mu \mathrm{g} / \mathrm{mL}$ & $72,6 \pm 1,0^{* *}$ & $>100$ & $\mathrm{NT}$ \\
FrHex & $6,4 \pm 1,0 \mu \mathrm{g} / \mathrm{mL}$ & $74,6 \pm 1,5^{* *}$ & $>100$ & $\mathrm{NT}$ \\
FrAcEOt & $5,0 \pm 1,0 \mu \mathrm{g} / \mathrm{mL}$ & $70,1 \pm 0,2^{* *}$ & $>100$ & $\mathrm{NT}$ \\
FrMeOH & $4,9 \pm 1,0$ & $71,4 \pm 1,2^{* *}$ & $>100$ & $\mathrm{NT}$ \\
& $\mu \mathrm{g} / \mathrm{mL}$ & & & \\
\hline
\end{tabular}

* Os resultados referem-se: ${ }^{a}$ Concentração inibitória a 50\% das formas promastigotas $\left(\mathrm{CI}_{50}\right)$ calculada através de curvas concentraçãoresposta tóxica e expressa como média \pm erro padrão da média; ${ }^{\mathbf{b}}$ Efeito máximo (EM) que é expresso como média da toxicidade máxima \pm erro padrão da média em triplicatas de um experimento representativo. Os valores de EM foram considerados significativos

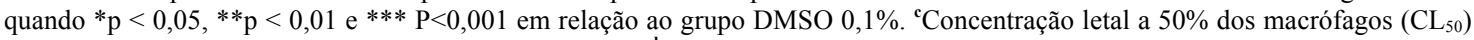
calculada através de curvas concentração-resposta tóxica. ${ }^{\mathrm{d}} \mathrm{Média} \pm$ erro padrão da média da citoxicidade na concentração de $10 \mu \mathrm{M}$ em triplicatas de um experimento representativo. Os valores de efeito máximo foram considerados significativos quando $* \mathrm{p}<0,05$, $* * \mathrm{p}<0,01$ e *** $\mathrm{P}<0,001$ em relação ao grupo DMSO 0,1\%; NT: substância não apresenta atividade letal significativa para os macrófagos nas concentrações de 100 e $10 \mu \mathrm{M}$ em relação ao grupo DMSO.

$\mathrm{O}$ extrato EEtOH e as frações FrMeOH e FrAcEOt exibiram as atividades leishmanicidas mais significativas, com valores de concentração inibitória mínima $\left(\mathrm{CI}_{50}\right)$ de 5,1, 4,9 e 5,0 respectivamente. O extrato etanólico e as frações orgânicas de hexano, acetato de etila e metanol-água, não afetaram a viabilidade das células J774, após 48 horas de incubação.

O gênero Prosopis inclui 44 espécies que são nativas das Américas do Sul e do Norte, das quais 28 espécies foram registradas como endêmicas destas regiões. Estudos químicos da espécie $P$. juliflora mostraram a presença de substâncias bioativas como alcaloides, flavonoides, terpenos e compostos fenólicos (HENCIYA et al., 2017). Atividades biológicas, incluindo, atividades antimicrobiana, antifúngica, antiinflamatória, analgésica e antitumoral, já foram registradas para a espécie $P$. juliflora (SHACHI-SINGH; VERMA, 2011; SATHIYA; MUTHUCHELIAN, 2011; NAPAR et al., 2012; RAVIKUMAR et al., 2012). Foram encontrados registros de atividade antiparasitária desta espécie, porém poucos trabalhos foram encontrados em relação a atividade leishmancida de $P$. juliflora. 
Musayeib et al. (2012), registraram atividade leishmanicida do extrato metanólico das folhas de $P$. juliflora frente a formas promastigotas de L. infatum $\left(\mathrm{CI}_{50}=35 \pm 2,6\right.$ $\mu \mathrm{g} / \mathrm{mL}$ ). Comparando os resultados desta pesquisa, com os dos autores supracitado, é possível observar que os extratos e frações de P. juliflora, apresentaram atividade mais significativa frente à espécie L. amazonensis. Segundo Wilson e Pearson (1990), as diferentes espécies do gênero leishmania produzem grande variedade de manifestações clínicas que dependem da interação entre a resposta imune do hospedeiro vertebrado e da invasividade, tropismo e patogenicidade destes parasitas.

\section{CONCLUSÃO}

Os resultados para a atividade leishmanicidad do extrato etanólico e das frações orgânicas hexânica, acetato de etila e metanol-água oriundos de P. juliflora, foram significativos para formas promastigotas de L. amazonensis, sem apresentar toxicidade para célula hospedeira. Os resultados promissores sugerem a realização de estudos químicos detalhados, para isolamento de substâncias; bem como a utilização destas em ensaios in vitro frente a formas promastigotas e amastigotas de L. amazonensis.

\section{REFERÊNCIAS}

ALVAR, J.; VE'LEZ, ID.; BERN, C.; HERRERO, M.; DESJEUX, P.; CANO, J.; JANNIN, J.; BOERL, M. WHO Leishmanisis control team. Leishmanisis Worldwide and Global Estimates of Its Incidence. PI On., v.7. n.5, p.e35671, 2012.

GRECCO, SS.; REIMÃO, JQ.; TEMPENO, AG.; SARTORELLI, P.; CUNHA, R LR.; ROMO, FFP.; FERREIRA, RJP.; FAVERO, DA.; LAGO, JH. In vitro antileishmanial and antitrypanossomal activies od flavonones from Baccharis retusa D.C. (Asteraceae). Exper Parasit, v.130, v.3, p.141-145, 2012.

HENCIYA S, SETURAMAN P, JAMES AR, TSAI YH, NIKAN R, WU YC, DAHMS, HU, CHANG FR. Biopharmaceutical potentialis of Prosopis spp. (Mimosaceae, Leguminosae). Jour of Foo and Drug Anal, v.25, n.1, p.187-196, 2017.

MOSMANN, T. Rapid colorimetric assay for cellular growth and survival: application to proliferation and cytotoxity assays. Jour Immun Meth, v. 65, p. 55-63, 1983.

MUSAYEIB, NM.; MOTHANA, RA.; AL-MASSARANI, S.; MATHEUSSEN, A.; COS, P.; MAES, L. Study of the in vitro antiplasmodial, antileishmanicidal and antitrypanosomal activities of medicinal plants from Saudi Arabia. Moll, v.17, n.1, p.11379-11390, 2012.

NAPAR, A. A.; BUX, H.; ZIA, A.M.; AHMAD, M. Z.; ROOMI, S.; MUHAMMAD, I.; SHAH, S. H. Antimicrobial and antioxidant activities of mimosaceae plants: Acacia modesta Wall, Prosopis cineraria (Linn) and Prosopis juliflora (Swartz). Jour of med plant resear, v.6, n.15, p.2962-2970, 2012.

NASCIMENTO, CE.; TABARELLI, M.; SILVA, CAD; LEAL, IR.; TAVARES, W.; SERRÃO, J. E.; ZANUCIO, JC. The introduce tree Prosopis juliflora is a serious threat 
to native species of the Brazilian caatinga vegetation. Scienc of the total environ, v.482, n.1, p.108-113, 2014.

RAVIKUMAR, S.; INBANESON, S. J.; SUGANTHI, P. In vitro antiplasmodial activity of ethanolic extracts of south Indian medicinal plants against Plasmodium falciparum. Asi Pacif Jourof trop disease, v.13, n.1, p.180-183, 2012.

SANTOS, APA.; PACHECO, SGA.; TELES CBG. Efeito leishmanicida in vitro do látex de Cronton lechleri (Euphorbiaceae). Rev de Ciên Farmac Bás e Aplic, v.36, n.3, p.413-418, 2015.

SANTOS KKA, ROLÓN M, VEJA C, ARIAS AR, COSTA JGM, COUTINHO HDM. Atividade leishmanciida in vitro de Eugenia uniflora e momordicacharantia. Rev de Ciên Farmac Bás e Aplic, v.34, n.1, p.47-50, 2013.

SHACHI-SINGH, S.; VERMA, SK. Antibacterial properties of alkaloid rich fractioons obtained from various parts of Prosopis juliflora. Intern Jour of Phar Scien and Resear, v.2, n.3, p.114-120, 2011.

SUKIRTHA, K.; GROWTHER, L. Antibacterial, antifungal and phytochemical analysis of sected medicinal plants. J Nat Prod Plant Resour., v. 2, n. 6, p. 644-648, 2012.

WILSON ME, PEARSON RD. Immunology of leishmaniasis. In: Wyler DJ (Ed). Modern parasite biology: cellular, immunological aspects. New York: WH Freeman, 1990. p. 200-221.

\section{AGRADECIMENTOS}

Ao Laboratório de Parasitologia da UPE, campus Santo Amaro, Recife-PE.

A Uninassau Caruaru. 